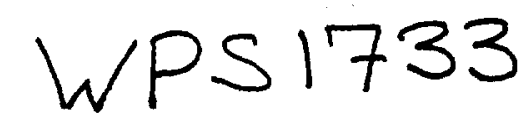

Policy Research Working Paper

The Usefulness of Private and Public Information for Foreign Investment Decisions

Yuko Kinoshita

Ashoka Mody $\therefore$

1733

$\because$ ind

ants:

$\therefore$,

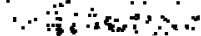

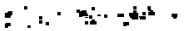

and

$-\pi x^{2}$

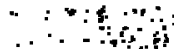

$\therefore=$

$\therefore$

$\therefore \therefore$.

$\therefore$.

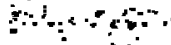

Information on operating

:- conditions based on direct

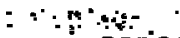

experience in a country is

$\therefore$ ans

$\therefore$ likely to be the information most credible to foreign investors. But for investors new to a country, information inferred from observing others investing in that country may be more - infiuential - and may lead to cascading investments in that country, as happened in China and Vietnam. Countries that do not draw a critical $\rightarrow$ thes of mass of investors are in danger of being bypassed by

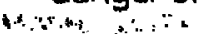

investors.
The World Bank

East Asia and Pacific Regional Office

February 1997 
POLICY REsearch Working Paper 1733

\section{Summary findings}

Using a specially designed survey of Japanese firms planning investments in Asia, Kinoshita and Mody emphasize the importance of privately held information in making foreign investment decisions.

Information on operating conditions based on direct experience in a country is likely to be the most credible information, but for investors new ro a country, information inferred from observing others investung in that country may be more influential. Initially, in fact, observing the actions of competitors seems ro lead $\omega$ cascading nnvestments in that country, apparently through herd behavior (as in China and Vietnam). Countries which do not draw a critical mass of investors are in danger of being bypassed for significant periods.

Publicly available information is important in helping shape "average" perceptions about a country, leading potential investors to view particular locations favorably. Privately held information complements that public information, and accounts for important variations in investment plans.

Subjective perceptions about policy on foreign direat investment are also important.

Policy designed io attract investors - for example, speciul zones for foreign investors - have been acceesful in many instances, especially in East Asia, but have also been a waste of scarce investnent resources when not appropriately planned. And such policy is of luttle alue in attracting those alrcady investing in a country, or those who already perceive rivals to be active there

This paper - a product of the East Asia and Pacific Regional Office - is part of a larger effort in the department to study trends in foreign investment in the region. Copies of the paper are av sliable free from the World Bank, $1818 \mathrm{H} \mathrm{Streer} \mathrm{NW,}$ Washington, DC 20433. Please contact Rafaela Reff, room Q5-139, telephone 202-473-4815, fax 202-477-0218, Internet address rreff@worldbank.org. February 1997. (32 pages)

The Policy Research Working Faper Series disseminates the findings of wn, in in progress to encourage the exchange of ideas about development issues. An objective of the series is to get the findings out auckly, even if the presentations are less than fully polished. The papers carry the names of the authors and should be cited accordingly. The findings, interpretations, and conclusions expressed in this paper are entirely those of the athers. They do not necessurily represent inc wete of the World Bank, its lixecutive Directors, or the countries they represent. 


\title{
The Usefulness of Private and Public Information for Foreign Investment Decisions
}

\author{
Yuko Kinoshita \\ New York University
}

Ashoka Mody

World Bank

This paper was initiated while Kinoshita was a consultant at the World Bank. The data for this paper were obtained through a special survey designed by Susmita Dasgupta, Ashoka Mody, and Sarbajit Sinha. Osamu Kawaguchi assisted in the preparation of the survey design and its implementation through the Ministry of International Trade and Industry in Japan. 
"...either he should discover the truth about them for himself or learn it from some one else; or if this is impossible, he should take the best and most irrefragable of human theories and make it the raft on which he sails through life." Plato.

\section{Introduction}

What information sources do investors use to make their decisions? Does privately-held information play an important role in the decision-making? If so, is the private information acquired through direct experience? Or is it based upon observations of actions undertaken by others? These questions are especially relevant for foreign investment decisions where public, or commonly-held, perceptions are characterized by considerable unce; tainty and, in particular, may be quite misleading for an investor's specific requirements.

In this paper, we demonstrate the empirical importance of private information, with others' actions being a specially important guide when "new" countries are opening up. Significant discontinuties in investment flows are observed at such times. China has attracted a rush of investment not only from overseas Chinese but also from U.S., Japanese, and European investors, starting quite abruptly in the late 1980 s and growing explosively into the mid-1990s. China receives about $\$ 40$ billion a year of foreign investment despite cumbersome procedures and uncertainty on property rights and contract enforceability; in contrast, India after rolling back restrictions and a longer tradition of a market economy chalks up less than $\$ 2$ billion a year. A similar discontinuity is now being observed for Vietnam, where competing investors are staking out their positions. Investors do use publicly available information on market size, stocks of infrastructure, costs of doing business (including labor costs), foreign investment policies, and other country characteristics to make new investment decisions. However, such information is rarely a sufficient guide to investment decisions. Moreover, public information-by definition, available to 
all potential investors - cannot lead to cascades unless new developments occur, as when a major policy initiative is announced. Policy initiatives do matter-however, as we show, their consequences depend upon private information. In contrast, privately-held information-or more accurately, private beliefs - can have a significant impact on investment flows even when no fundamental change has occurred but when a perception of change leads to actions by a critical mass of investors, which then has a snowballing effect. In practice, public and private information complement each other. They also interact: certain publicly announced, though minor, events can reinforce latent private beliefs, which may then become the primary drivers of foreign investment.

What is the content of private information? Investors seek information on a variety of operational conditions which are not publicly available, including the functioning of labor markets, industrial literacy of the workforce (as distinct from educational attainments), the practical implementation of foreign investment polices, and the timely availability of inputs. Such information may be acquired in two ways: through direct experience via past investments in a country and through inferenences from the behavior of other investors. Where a firm's past investment is the influence on future investment, we refer to that as a "learning" effect: presence in an earlier period generates valuable information on market and cost conditions which forms the basis for making new investments. Such information, this paper shows, is considered very valuable by investors; but, by definition, it is not available to new investors in a country.

Where the behavior of other investors spurs investment, we infer the influence of reputation and of strategic rivalry. A rivals' decision conveys the information that the rival considers investment in a particular country to be a profitable venture, thus increasing the incentive to invest in that country to benefit from the same opportunities. The importance of such intrinsically valuable 
information on operating conditions in a country is notably illustrated by General Motors' decision to locate its Asian hub in Thailand: "...the fact that 11 car manufacturers already operate in Thailand was a sign that the country's infamous physical infrastructure and labor bottlenecks could be overcome" (Bardacke 1996). However, this example also highlights that, in addition, private beliefs may reflect strategic considerations, which may also lead to a self-reinforcing cycle of investment (Kuran 1995). Anecdotal evidence suggests that the strategic element of such investment decisions is important. ${ }^{\prime \prime}$ While the learning effect creates persistence through inducing continued investments by existing foreign investors, inferences based on reputation of others and on strategic rivalry considerations leads more directly to "herd" behavior.

This paper draws upon two streams of literature: the economics of private information flows and beliefs and the determinants of foreign investment. Herd behavior parallels and reflects "cascades" of information flows (Scharfstein and Stein 1990, Bikhchandani, Hirshleifer, and Welch 1992, and Lee 1993). The so-called "herd" behavior—actions based on others' actions—can be quite rational in as much as it economizes on the gathering of scarce information. Arthur (1995) discusses several examples from economics and finance where private beliefs play an important role. Kuran (1995) explains the persistence of several social institutions as well as their abrupt breakdown on the basis of privately-held but publicly concealed preferences.

The influence of rivalry in driving foreign investment was examined in a pioneering study by Knickerbocker (1973). He showed that the more oligopolistic an industry, the greater was the

1/ The rush of Japanese motorcycle investors to Vietnam has followed from a perceived "first mover" advantage. Referring to the general interest in Vietnam, a German investor recently summarized well the phenomenon: "We simply cannot sit back and let the Japanese take over another market unchallenged" (Financial Times, March 28, 1995). 
likelihood that foreign investments would be concentrated into a short period of time, and hence display spikes or discontinuities in foreign investment flows. Knickerbocker did not, however, study the influence of past presence. Recently, Head, Ries, and Swenson (1995) have shown that Japanese investors in the United States tend to "follow-the-leader," affirming the signalling value of others' behavior. Kogut and Chang (1996) have used firm-level data for Japanese multinationals investing in the United States and they find past presence to be an important predictor of new investments-however, they do not explore the influence of rivalry. The findings of this paper are also consistent with aggregate evidence of persistence in foreign investment. Wheeler and Mody (1992) found that U.S. investments into a country were strongly conditioned by existing stocks of foreign investment in that country (after controlling for a variety of factors, including market size) and speculated that agglomeration economies may be important especially where investors were likely to be engaged in the purchase of intermediate inputs from other investors. But even where agglomeration economies are unimportant, past presence can provide, or the presence of others can signal, information on business operating conditions which are critical to smooth functioning but which cannot be easily inferred from generally reported statistical indicators or from stated policy towards foreign investors. Also, subsequent analysis shows that Japanese investors are equally influenced by the stock of past investment (Mody and Srinivasan 1996). This study reinforces earlier micro and aggregate evidence on the value of private information but additionally distinguishes between the different sources of private information and demonstrates their complementarity with public information.

The setting for the empirical examination is investment by Japanese manufacturing firms in a number of key Asian countries in the early 1990 s and the data is from a specially designed survey 
of Japanese investors. The next section describes the questions asked in the survey, the data thus generated, and the analysis methodology. We then present the simplest model that reveals the role of private information in determining a firm's likelihood of investing in a country and distinguishes between the influence of learning and rivalry among the sampled firms. We examine the robustness of the finding by introducing several firm characteristics in the estimated equation to determine if the "private information" merely reflects firm attributes. The role of public information on investment decisions is dealt with by introducing country dummies, which are assumed to embody information available to all; also, since public information is assumed accessible to all, regressions for individual countries help further highlight the role of private information. Successive models add other host country features that influence the behavior of foreign investors; interaction of learning and rivalry with these factors provides additional perspectives on foreign investment flows.

\section{Data and methodology}

The survey questionnaire was mailed by the Japanese Ministry of Trade and Industry (MITT) to several hundred Japanese firms of which 173 returned usable responses in March 1993. The sample thus obtained cannot be treated as representative of all Japanese firms-we do not know the characteristics of firms who did not respond. There is, however, sufficient heterogeneity amongst the respondents to permit a statistical analysis of their foreign investment behavior. The firms in our sample are relatively large. The average annual sales are 330 billion yen (over $\$ 3$ billion), the largest firm in the sample has sales of $\$ 70$ billion and the smallest has sales of $\$ 2$ million. This is also a set of firms that is prone to making significant foreign investments-in the three years prior to the survey, over a fifth of their investment was undertaken outside Japan. 
Our dependent variable is based on the following question regarding the firm's expectation that it will invest in specific Asian countries: "In each of the following countries, how likely are you to invest in the next three years?" Respondents were asked to check a space on a 1-7 scale provided, ranging from "very unlikely" to "very likely".

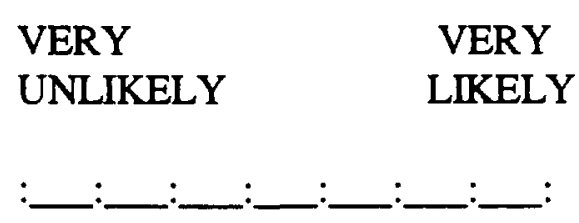

The question was answered for the following seven countries: China, Thailand, Malaysia, Indonesia, Vietnam, Philippines, and India. These countries constitute the principal developing country recepients of foreign investment in Asia. Their level of economic development is substantially lower than in the so-called Asian Tigers-South Korea, Taiwan, Hong Kong, and Singapore-with Malaysia being the closest to the Tigers by most development measures. For each of the seven countries, we have 173 responses, potentially creating 1211 (173x7) observations (however, since all respondents did not answer all questions, for certain estimations fewer usable observations are available and where appropriate we have tested for selection bias).

Our two key independent variables are PAST and RIVAL. The questionnaire asked whether the firm already had a presence in each of the seven countries being studied. For each firm and each country, the PAST variable was coded 1 if the firm was present in the country and 0 if it was not. Recall that we infer a learning effect if past presence leads to a high likelihood of future investment. The other key variable allowed inference on the information obtained from competitors and the extent of strategic rivalry. The question asked was: "Are your competitors making investments in 
the following Asian countries?" Once again, the response allowed ranged on scale of 1 (very little) to 7 (very substantial).

The average value of the responses for the seven countries (and the standard deviations) are reported in table 1. Respondents to our survey are most likely, by far, to invest in China, the average measure on the 1-7 scale for China being 4.08. Only 20 percent of the firms have existing investments in China; however, the perceived level of rivals' interests in China is high, second to Thailand. Four countries have similar likelihoods of investment: Thailand, Malaysia, Indonesia, and Vietnam. Of these, Malaysia and Thailand have traditionally attracted substantial Japanese interest, with 25 and 30 percent of firms respectively reporting existing presence in those countries; and rivals are also strongly interested. In contrast, Vietnam has low existing Japanese presence and also a relatively low interest from rivals. The least attractive sites are the Philippines and India, with low expected investment, low initial presence, and low rivals' activity. Thus, a simple comparison across countries indicates a correlation between expected investment by the firm and its perception of the strength of rivals' interest in the country. Since past presence is indicated only in 15 percent of the possibilities, information provided by behavior of rivals is likely to be valuable where the firm is entering new countries.

An ordered logit model was used to investigate these relationships more precisely. The model is an extension of the binomial logit model: instead of two choices, we here have three ordered choices (see Greene 1993). For the purpose of the regression, the likelihood of investment (LFDI) variable was rescaled. As illustrated, the original data is on a scale of 1 through seven. This was reconstructed to create three categories: 2 (highly likely to invest where the response was 6 or 7), 1 (moderately likely, where the response was 3,4 , or 5), and 0 (unlikely to invest, where the response 
was 1 or 2). As in the binomial logit model, we assume a latent regression model of the following form:

$$
y^{*}=\beta x+\epsilon
$$

The latent variable $\mathrm{y}^{*}$ is not observed, but the response indicating the likelihood of investment is observed. The observed responses are related to the latent variable in the following manner:

$$
\begin{aligned}
& y=0 \quad \text { if } y^{*} \leq 0 \\
& y=1 \quad \text { if } 0<y^{*} \leq \mu \\
& y=2 \quad \text { if } \mu \leq y^{*}
\end{aligned}
$$

Then, for the logistic cumulative distribution function, the model predicts the following probabilities for each of the responses:

$$
\begin{gathered}
\operatorname{Prob}(y=0)=\Lambda(-\beta x) \\
\operatorname{Prob}(y=1)=\Lambda(\mu-\beta x)-\Lambda(-\beta x) \\
\operatorname{Prob}(y=2)=1-\Lambda(\mu-\beta x)
\end{gathered}
$$

The joint probability or the likelihood function is:

$$
L=\prod_{i=1}^{n}\left[\operatorname{Pr}\left(Y_{i}=0\right)\right]^{d_{i 0}}\left[\operatorname{Pr}\left(Y_{i}=1\right)\right]^{d_{i u}}\left[\operatorname{Pr}\left(Y_{i}=2\right)\right]^{d_{i 2}}
$$


where $d_{i k}(k=0,1,2)$ is an indicator function equal to 1 if $y_{i}=k$ and zero otherwise. " $n$ " is the number of observations, where the observational unit is a firm's investment plans for each country, implying up to seven observations per firm. The parameters are estimated by maximizing the log of the likelihood function.

For the analysis, the RIVAL response was condensed into a binary variable: RIVAL was 0 where the response was 1-4 (competitors uninterested or mildly interestd in investing in that country) and was 1 where the response was 5-7 (competitors seriously interested). As will be evident below, summary of RIVAL into a binary variable greatly facilitates comparison with the effects of PAST. Regressions were also performed with the variable retained in its original 1-7 scale and with RIVAL scaled as $0,1,2$ with qualitatively similar results.

\section{The base model: privately held information}

At the risk of misspecification, we first highlight the value of privately held information by regressing the firm's likelihood of investing in a particular country against its past presence or absence in that country (PAST) and perceptions about competitors' interest in that country (RIVAL). The danger of misspsecification arises on account of omitting other relevant variables, including firm characteristics and the role of publicly available information; however, as show below, the basic results of this section hold up even in more fully specified models. We pooled the data for all countries thus assuming that the effects of learning and rivalry are the same in the different countries considered. 
The results of the ordered logit are presented in table 2. From column 1 it is clear that the both the firm's past presence and its perception of competitors' behavior has a strong influence on its plans to invest in a country. The coefficient on PAST (1.80) is somewhat higher than on RIVAL (1.41). Prima facie this implies that own experience has greater value than the information inferred from the behavior of rivals, which is a plausible finding. However, it is also likely that there exists greater measurement error in the RIVAL variable, which would bias downwards the coefficient on that variable.

The distinction between the two information channels becomes sharper when we interact them and add the interaction term as an additional variable (column 2 of table 2). This model is statistically superior to the first model discussed: inclusion of the PAST*RIVAL variable improves the log-likelihood and from the likelihood ratio test we can conclude (at the 2.5 percent significance level) that the interaction term belongs to the model.

The results are interesting. The two channels of private information appear primarily as substitutes for each other, though a certain degree of complementarity in suggested. The sign of the interaction term is negative and its size, 0.96 , is large. Consider the coefficient on PAST in this regression, which has risen from 1.80 in the previous regression to 2.30. The influence of PAST on future investment decisions is reduced when RIVAL is equal to 1: the firm places a reduced (though still substantial) value on its own experience (down from 2.30 to 1.34 ). Similarly, past experience devalues information from rivals' behavior quite significantly: when PAST is 1, then the coefficient on RIVAL falls from 1.63 to 0.67 (1.63-0.96). This seems a plausible result. A firm's experience with operational conditions is likely to carry greater weight in its calculus than inferences based on what others are doing. Moreover, any strategic considerations, such as the need for preemptive 
positioning in the market, are also not important to those who already have a presence in the country, limiting the need to respond with greater investment when others are perceived to be active. However, note that when both PAST and RIVAL equal 1, then both are influential-and while past carries greater weight, those with existing presence do watch and act on rivals' behavior.

Another perspective on these results is obtained by estimating the model's predicted probabilities for the likelihood of foreign investment. ${ }^{2}$ When PAST and RIVAL are both zero, the model predicts a 93 percent probability that foreign investment will be very unlikely $(y=0)$. With RIVAL $=0$, increasing PAST from zero to one, decreases the probability of $y=0$ by 24 percentage points to 69 percent, with the bulk of the increase -17 percentage points-occuring for $y=1$ (moderately likely) and a 7 percentage point increase for $\mathrm{y}=2$ (highly likely). In contrast, when RIVAL $=1$, increasing PAST from zero to one has a stronger effect: the decrease in probability of $y=0$ is 41 percentage points, and $y=2$ experiences a 22 percentage point increase. Thus, though the primary influence of PAST presence is exerted irrespective of whether strong rivalry is associated, the positive interaction of PAST and RIVAL is clearly indicated. A similar result is obtained when PAST is the control variable and RIVAL is varied from zero to one.

Taking the analysis one step further, we introduce firm dummies into the regression (column 3, table 2). Recall, we have multiple observations for each firm (with a maximum of seven observations where a likelihood was reported for each country). By introducing the firm dummies we are able to judge whether for each firm, $j$, certain unobserved firm reporting characteristics $\left(\eta_{j}\right)$ are associated with the variables PAST and RIVAL. If these unobserved characterisitics, which are

2 The probabilities are calculated using the set of equations (3) and following Greene (1993), pp. 675-676. 
part of the composite error term $\left(\epsilon_{\mathrm{ij}}=\eta_{\mathrm{j}}+\gamma_{\mathrm{ij}}\right)$, are correlated with PAST and RIVAL, then the coefficients will be biased. By adding firm dummies to the regression, the unobserved characteristics become part of the set of regressors and the error term now has only the white noise component, $\gamma_{\mathrm{ij}}$. Introduction of the firm dummies strengthens the result both in the size of the coefficients and statistical significance. The increased coefficient sizes on the PAST and RIVAL variables suggests that the composite error term is negatively correlated with these variables: in other words, those who have past presence or perceive active rivals are generally more conservative in their reporting their investment likelihood.

This simple model does well in predicting the outcomes. The model with firm dummies correctly predicts 75 percent of the stated likelihoods of foreign investment (table 3 )..$^{3 /}$ The "very unlikely" statements are almost fully predicted. The prediction rate for the "very likely" category is 53 percent. The model prediction rate (at 39 percent) is the lowest for the middle group, with a significant number of firms predicted to have a lower likelihood of foreign investment than the firms' stated intentions. The implication is that a number of firms with PAST and RIVAL equal to zero have moderately aggressive foreign investment plans-possibly, high production costs in Japan are having a general effect of pushing firms to seek lower cost production locations.

Preliminary analysis in this section, therefore, affirms the importance of information cascades but highlights the need to distinguish between the two channels through which information flows may occur and finds, moreover, that these two channels are principally substitutes for each other. Where past presence exists, it appears to be the more credible information source. However, only

3/ Without the firm dummies the match between model predictions and firms' statements is 68 percent. 
a small number of firms have past experience in this set of countries: as table 1 shows, only 15 percent of all possible firm-location combinations are occupied—less than 50 firms in the sample operate even in Malaysia and Thailand, the countries with the highest presence. Thus the behavior of rivals may be the more important source of information even if it is less valuable than own experience.

\section{Firm characterisitics: do they correlate with information flows?}

If past presence and perception of rivals' behavior were correlated with firm characteristics, we might be incorrectly attributing foreign investment decisions to particular information flows than to specific features of the firms. To examine this possibility we introduced firm size (measured by worldwide sales), the research and development (R\&D) ratio, and export propensity into the regression equation. Table 4 reports the results. The first column repeats the basic regression for comparison with table 2 , since we have lost some observations. The main thing to note is that the results are essentially the same though we have fewer obserations.

The second column shows the effect of introducing the firm characteristics. Larger firms have higher expected foreign investment. $R \& D$ has only a weak positive relationship to expected investment; since R\&D and size are correlated, it is not surprising that once the influence of size is controlled, then any independent influence of R\&D is not disernible. Finally, firms expecting to investment significantly in Asia have a low export propensity.

For the present analysis the important observation from this set of regressions is that there is virtually no change in the basic results that are the focus of this paper. The coefficient on the RIVAL variable remains unchanged. The coefficient on PAST falls somewhat in magnitude but 
remains statistically significant at the 1 percent level. Thus it appears that the sources of information embodied in PAST and RIVAL bear no simple relationship to firm characteristics. Moreover, the information contained in PAST and RIVAL has a much more important bearing on foreign investment than do firm characteristics: the log-likelihood changes little when the firm characteristics are introduced as explanatory variables.

To further explore the influence of firm characteristics, we focus on size and examine if particular size classes have special affinity to particular information sources. Firms are divided into three size groups or stratas. Table 5 reports the results of regressions with three dummy variables for strata 1 (small firms, annual sales of 2-100 hundred million yen), strata 2 (medium-sized firms, sales between 100-1000 hundred million), and the benchmark strata 3 (large firms, sales over 1000 hundred million). Note first that this set of results confirms that larger size is associated with a greater likelihood of investment. Of interest are the interactions between size groups and PAST and RIVAL. Small firms place a great weight on past presence, which significantly increases their likelihood of new investment. In other words, while small firms are the least likely to make new investments, the likelihood of continued investment in a country where they have invested in the past is substantially higher. The data, therefore, suggest that small firms face barriers to initial investments abroad but once having taken the leap are aggressive learners. In contrast, mediumsized firms are much more driven by and sensitive to the actions of rival firms than are large or small firms. Medium-sized firms have a smaller presence abroad than large firms and so have less basis to draw on that source of information but, unlike small firms, are likely to place greater weight on strategic considerations. 


\section{Country effects: the role of public information}

The regressions above could be falsely attributing to privately held information a value that does not exist if information from private sources were collinear with and equally available from public sources. Clearly, public information sources do influence the foreign investment decision. Firms obtain information through analytical country reports by international organizations such as the World Bank and the International Monetary Fund and also by a growing range of private consulting firms; and the media provides continuing reports on a range of political, economic, and social attributes of countries. As a consequence, investors form assessments of countries from such widely available information on a large number of factors including market size, growth prospects, costs of production, the state of infrastructure, and the country's political and institutional development.

The further analysis in this section, therefore, explores two sets of questions. First, once

firms' perceptions of different countries are controlled for, do the effects of past experience and rivalry continue to be important? In other words, are the results of the base model robust to differences in publicly perceived attractiveness of countries considered? Second, do PAST and RIVAL influence investment to varying degrees in the different countries?

To answer the first question, we augmented the basic regression with country dummies which capture in a summary form the relative attractiveness of the different countries. Since the coefficients on the dummy variables represent the average perception of the country, we take these to represent the publicly available information. An alternative specification would include specific country features, such as infrastructure, market size, and labor costs. As Head, Ries, and Swenson (1995) have argued, a full elaboration of country characteristics is difficult, and hence a country 
dummy which captures in summary form the country's attractiveness to the "average" investor is preferred in this situation. In the next section, we do examine the effects of specific country features. The regressions in table 6 leaves out Vietnam, which is consequently the reference against which the attractiveness of other countries is measured.

The robustness of the PAST and RIVAL effects is evident (table 6). Both variables are significant at the 1 percent level as in the base regression and the coefficient values are also similar, with PAST coefficient somewhat larger than that of RIVAL. This finding reaffirms the value of privately held information and its possible cascading effects. The regression also highlights the complementary role of private and publicly available information: general perceptions of a country based on publicly-held information are also influential in driving investment flows. The loglikelihood when the country dummies are included is significantly different from the corresponding regression in table 2 , indicating that significant information is contained in these country dummies and hence in the generally held view of the country. Private information complements the public information sources, which can only describe the general state of the country and not the business operating conditions and the actual implementation of the policy regime.

The country dummies also elicit useful information. With Vietnam as the reference, on average, investors express a strong preference for China. Indonesia, Thailand, and Malaysia are likely to be somewhat less sought after, though the coefficients are not statistically different from zero, indicating about parity with Vietnam. Two countries lowest on the preference list are the Philippines and India. Note also that the coefficients on firm characteristics remain very similar when country dummies are added, indicating yet another influence on foreign investment flows.

In terms of goodness of fit (table 3), the predictive power of the model improves somewhat 
overall from 75 to 79 percent. The increase is mainly in the "very likely" category and especially in the "likely" category, where the "hits" now go up from 39 to 50 percent, implying that countries that previously predicted as unlikely to undertake investment are being attracted by the generally perceived attractiveness of investment sites in China and south-east Asia.

Next, given the strong differences in country preferences as indicated by the coefficients on the country dummies, we explore whether the privately-held information is used or valued differently depending upon the country contexts. Individual regressions are run for each of the seven countries (table 7). Several features of these results are worth highlighting. The signs for the PAST and RIVAL coefficients for each of the countries are the same as for all countries pooled together and the magnitudes of the coefficients all fall in a similar range (except for the coefficient on PAST for Vietnam, where there has been virtually no past investment and the interaction term for India which is very large with a large standard error). Also, eight of the 14 coefficients (seven each on PAST and RIVAL) are significant at the 1 percent level and three at the 5 percent level.

Some interesting country variations are worth highlighting. For India, Philippines, and Vietnam, where the PAST variable is not statistically significant, the extent of past presence is also very small, limiting the statistical predictive power of that coefficient. For Vietnam, the coefficient on RIVAL is very large, suggesting that firms are very sensitive to perceived actions of rivals and hence the possibility of a cascading effect. Though the effect is smaller, a similar force may well be operative for India. At the other extreme, in Malaysia, where significant past presence exists, the effect of RIVAL is negligible for those who are already operating in that country; however, even in Malaysia, new entrants are signficantly guided by the actions of rivals. In this respect, Thailand is different from Malaysia: though a signficant past presence exists there, existing investors in Thailand 
do appear influenced by the behavior of their rivals.

The conclusion from this set of regressions, therefore, is that public information, as captured by the country dummies, is important in influencing foreign investment plans. Such information is, however, complementary to private information obtained through past investment in the country or transmitted by other firms by their investment actions in that country. Country differences in the influence of PAST and RIVAL appears to depend in large part upon the extent of the installed base of investors in that country.

\section{Can governments influence private information?}

These findings raise important questions for policymakers. If privately held information is important and complementary to publicly available information, then what role should policy play in attracting foreign investment? Should it be limited to improving the enabling conditions and ensure that these are well-publicized? That would be a legitimate task, for as we have seen publicly available information is clearly important in guiding foreign investment flows. Or should policymakers adopt a proactive stance at influencing private information? If the latter course is to be pursued, then the nature of such information or at least its correlates need to be identified.

In this section we explore specific country characteristics that may be correlated with privately held information. The survey questionnaire asked respondents to rank several country characteristics on a scale from unfavorable to favorable. While "objective" measures may be used to differentiate countries, the reported perceptions reveal the subjectively held views, which is our interest. Several country features were explored; here we highlight three of them: foreign direct investment (FDI) policy, labor costs, and market size. In doing so, we are handicapped by a reduced 
number of observations to work with since many respondents did not provide the ratings on country characteristics. As such, there is some danger here of a selection bias in the results. However, since the coefficients on PAST and RIVAL remain similar to the earlier results, we can have some confidence that the extent of the selection bias is not large. Formal tests confirmed the absence of selection bias. ${ }^{4 \prime}$

FDI policy was explained to respondents to include such elements as the ability to repatriate earnings, restrictions on foreign ownership, and the requirements to export and source inputs locally. Perceptions of FDI policy are strongly influential in conditioning future plans to invest in a country (table 8, column 1). The coefficient on FDI policy is positive and significant at the 5 percent level. Note, however, that the coefficients on PAST and RIVAL also remain positive and significant at the 1 percent level. Thus, the evidence seems to suggest that FDI policy is additional information to that obtained by from past investment experience and actions of competitors.

Though representing additional information, perceptions of FDI policy interact in interesting with ways with PAST and RIVAL. Notice that the coefficient on the interaction term, FDIplcy*past is negative. Hence when past is equal to 1 -i.e., when the firm has a past presence in that country-the effect of FDI policy is more than wiped out. In other words, perceptions of FDI policy matter little when the firm has first-hand operational experience in the country. The corollary is that perceptions of good FDI policy are especially important in attracting new investors. In this sense,

4' A reporting equation for the country characteristics (e.g., FDI policy) was first obtained with a dependent variable $\mathrm{z}$ if that characteristic was reported equal to 1 and zero otherwise. The variable $z$ was regressed on firm characteristics: size, $R \& D$, and export propensity. The predicted values of $z$ were used to estimate "lamda" or the inverse Mills' ratio. The investment equation was reestimated with lamda as an additional variable. Since the coefficient on lamda was insignificant, the absence of selection bias is indicated. 
the two types of information are complementary not for individual investors but rather from the perspective of a country's policymaker: improving the working conditions is likely to be effective for past investors and a liberal FDI policy is more relevant for first-time investors.

FDI policy has a very similar interaction with RIVAL. Where rivalry is important, it overwhelms the influence of FDI policy: firms rely to a much greater extent on the actions of rivals than on their perceptions of FDI policy, however favorable. This finding is consistent with General Motors' decision to invest in Thailand, following decisions by several autombile and auto parts manufacturers to locate in Thailand, despite very generous incentives offered by the Philippines, which Thailand was unable to match (Bardacke 1996). The finding may also explain the rush into China, where policies and legal operating conditions remain unclear to many Western investors.

The implications for the policymaker are complex. FDI policy does not appear to be a key element of privately-held information that drives foreign investors. A favorable impression of FDI policy is desirable when investors have no direct country experience or when competing investors are not already planning to or undertaking investments in the country. Once investment begins to occur, the role of privately-held information acquires significant importance. However, a favorable FDI policy continues to be important to the extent that it minimizes the reliance of firms on privately-held information, inducing them hopefully to make their investment decisions on the basis of country fundamentals.

We also explored the possibility that privately-held information may correlate with perceptions of labor costs in the country. While costs of production depend upon a variety of factors, labor costs are thought of as an important attraction of this set of Asian host countries. As with FDI policy, we added perceptions on labor cost as an additional variable to the basic regression. Where 
labor costs are perceived as being low, the likelihood of future investments does increase significantly (a favorable labor cost receives a high score and hence a positive sign on that coefficient). But once again, the influence of PAST and RIVAL remains largely unchanged. Thus the inference again is that perceptions of labor cost while important are not the essence of the privately-held information but rather a complement to that information. The terms interacting perceived labor costs with PAST and RIVAL are positive, though the interaction with past is not statistically significant. In contrast, therefore, to perceived FDI policy (which becomes less importance when private information is available), labor costs actually grow in importance when privately-held information exists.

Finally, a larger market size also improves the improves the attractiveness of a country to Japanese investors (the results are not presented in the interests of space but are available on request from the authors). The interaction with RIVAL has no influence, but the interaction with PAST has a negative and significant sign (at the 5 percent level). Thus, past presence reduces the influence of a large market size.

\section{Conclusions and discussion}

Using a firm-level data set, we explored the empirical importance of privately-held information in foreign investment location decisions. Though the limitations of a one-time survey did not permit us follow an information "cascade" over successive generations, the value of private information, which is central to the cascade phenomenon was consistently and impressively evident.

The data permitted us, moreover, to distinguish between two types of private information: one that was obtained through direct experience in the host country and the other that was inferred 
from observing competitors. Direct experience is seen to provide the more credible information, as may be expected. However, in the early phases of investing in a new country when few firms have experience in the country, the actions of competitors are likely to be dominating effect, leading to an apparent herd behavior. Such is apparently the case currently for China and Vietnam, which are attracting large numbers of new investors. In contrast, countries, such as India and the Philippines, that do not draw the attention of a critical mass of investors are in danger of being bypassed for significant periods of time.

We enquired how the privately-held information could was related to publicly available information and found it to be complementary. Thus, while firms form "average" perceptions about a country leading them all to view particular locations favorably, considerable variation in investment plans exists around these averages-an important element of such variation is explained by privately-held information. We explored also whether private information was a proxy for subjective beliefs on certain country characteristics: FDI policy, labor costs, and market size. Again, the finding was that while such subjective perceptions are important, they represent additional information to that obtained through either past experience or through observing others.

For policymakers, these findings represent a challenge. A generally favorable view of the country based on its fundamentals as well as perceptions of good policy and low labor costs lead to increased foreign investment. However, creating the right conditions for investors to directly experience the rigors of operating in a country is empirically important, as is the opportunity to observe competitors. This raises the controversial issue of special zones for foreign investors. While successful in many instances, especially in East Asia, they have also been a waste of scarce investment resources where not appropriately planned. An emerging approach is for the government 
to take the lead in creating the policy conditions for the creation of such zones but allow private investors to undertake the necessary investments and thus ensure greater efficiency. Mexico offers an example. Under the maquiladora program, the policy environment has been created to attract foreign investors. Several private initiatives have resulted in so-called "shelters" that provide early hand-holding services to new foreign investors. 


\section{REFERENCES}

Arthur, Brian. 1995. "Complexity in Economic and Financial Markets." Complexity, John Wiley \& Sons, Inc., 20-25.

Bardacke, Ted. 1996. "General Motors'Thai Hub will Boost Drive Into Asia." Financial Times, May 31.

Bikhchandani, S., D. Hirshleifer, and I. Welch. 1992. "A Theory of Fads, Fashion, Custom, and Cultural Change as Informational Cascades." Journal of Political Economy 100 (5): 922-1026.

Greene, William. 1993. Econometric Analysis. Second Edition. Englewood, N.J.: Prentice Hall.

Head, Keith, John Ries, and Deborah Swenson. 1995. "Agglomeration Benefits and Location Choice: Evidence From Japanese Manufacturing Investments in the United States." Journal of International Economics 38: 223-247.

Knickerbocker, Fredrick T. 1973. Oligopolistic Reaction and Multinational Enterprise. Boston: Harvard University, Graduate School of Business Administration.

Kogut, Bruce and Sea Jin Chang. 1996. "Platform Investments and Volatile Exchange Rates: Direct Investment in the U.S. by Japanese Electronic Companies." The Review of Economics and Statistics 78 (2): 221-231.

Kuran. Timur. 1995. Private Truths, Public Lies: The Social Consequences of Preference Falsification. Cambridge, MA: Harvard University Press.

Lee, I. H. 1993. "On the Convergence of Informational Cascades." Journal of Economic Theory December: 395-411.

Mody, Ashoka and Krishna Srinivasan. 1996. "Japanese and United States Firms as Foreign Investors: Do They March to the Same Tune?" Mimeographed, The World Bank and The International Monetary Fund, Washington D.C.

Scharfstein, D. and Jeremy Stein. 1990. "Herd Behavior and Investment." American Economic Review 80: 465-479.

Wheeler, David and Ashoka Mody. 1992. "International Investment Location Decisions: The Case of US Firms." Journal of International Economics 33: 57-76. 
Table 1. Descriptive statistics: country averages of principal variables

$\begin{array}{llll}\text { Investment Plan } & \text { Past Presence } & \text { Rivals' Activity } & \text { Investor Perceptions (Scale: 1-10) } \\ \text { (Scale: 1-7) } & \text { (Yes=1, No=0) } & \text { (Scale: 1-7) } & \text { FDI policy Labor Cost }\end{array}$

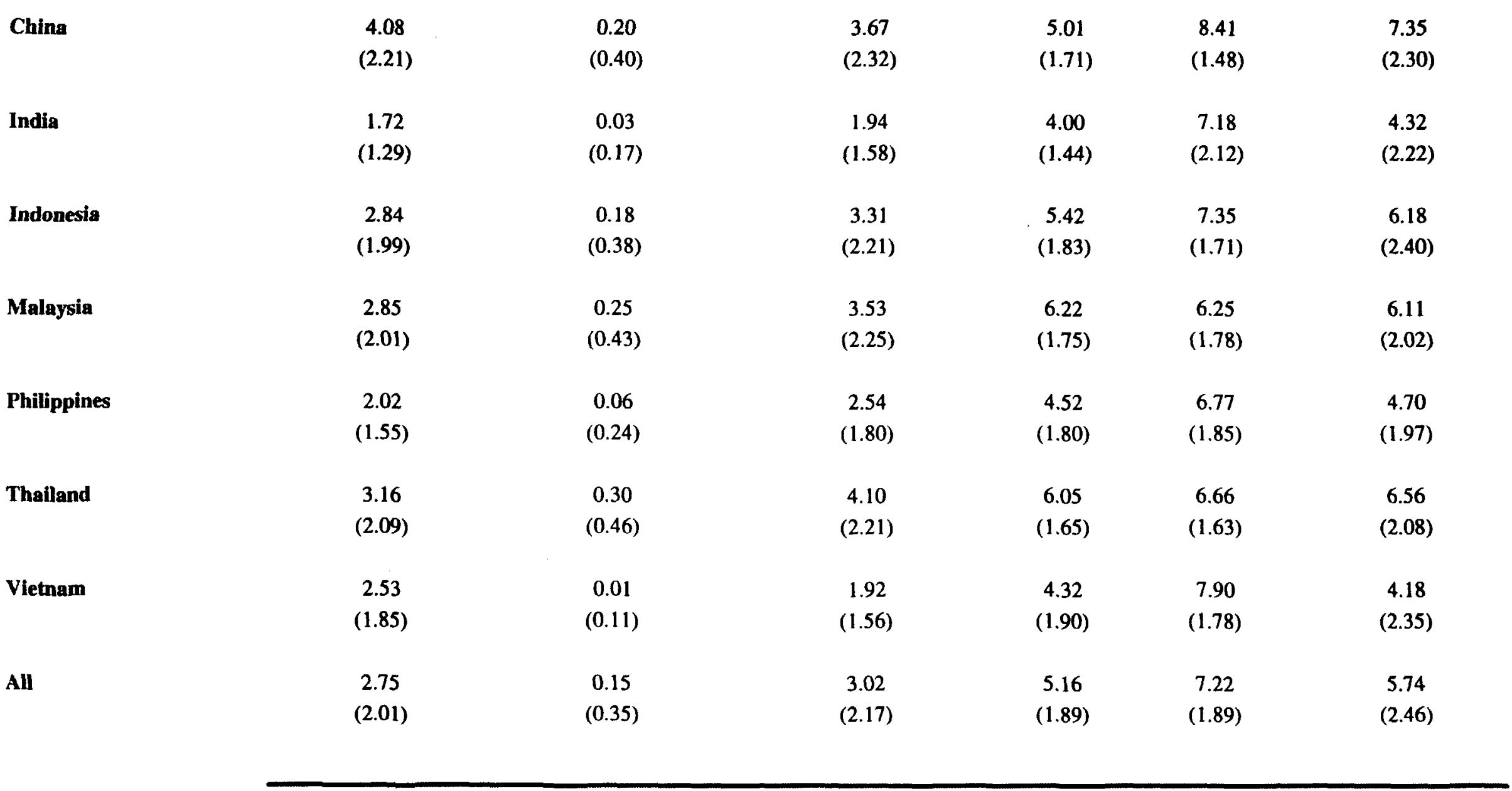

Note: Parentheses are standard errors. 
Table 2. The base model :value of private information dependent variable $=$ LFDI (likeihood of FDI)

[1] [2] [3]

\begin{tabular}{lccc} 
& $-2.61^{* *}$ & $-2.66^{* *}$ & $-5.52^{* *}$ \\
intercept & $(0.12)$ & $(0.12)$ & $(0.32)$ \\
past & $1.80^{* *}$ & $2.30^{* *}$ & $2.78^{* *}$ \\
& $(0.20)$ & $(0.28)$ & $(0.38)$ \\
rival & $1.41^{* *}$ & $1.63^{* *}$ & $2.03^{* *}$ \\
& $(0.16)$ & $(0.18)$ & $(0.26)$ \\
past*rival & & $-0.96^{*}$ & $-1.44^{* *}$ \\
& & & $(0.50)$ \\
$\mu$ & 1.50 & 1.51 & 2.09 \\
firm dummies & no & no & yes \\
country dummies & no & no & no \\
n & & & 997 \\
logliklihood & 997 & -777.70 & -589.75 \\
\hline
\end{tabular}

Note:

(1) Parentheses are standard errors. ${ }^{* *}$ and $*$ indicate $1 \%$ and $5 \%$ significance level, respectively.

(2) $\mu$ is the second intercept defining the threshold for the transition from LFDI equal to 1 to 2. 


\section{Table 3: Model predictdictions: "hits and misses"}

A: [lfdi=f(past, rival, past*rival, and firm dummies)]

\begin{tabular}{|c|c|c|c|c|}
\hline & predict $=2$ & predict $=1$ & predict $=0$ & total \\
\hline observe $=2$ & $\begin{array}{c}80 \\
(.53) \\
\end{array}$ & 36 & 33 & 149 \\
\hline observe $=1$ & 38 & $\frac{83}{(.39)}$ & 93 & 214 \\
\hline observe $=0$ & 8 & 38 & $\frac{588}{(.93)}$ & 634 \\
\hline total & 126 & 157 & $7 \overline{714}$ & $\begin{array}{c}997 \\
(.75)\end{array}$ \\
\hline
\end{tabular}

B: [lfdi=f(past, rival, past*rival, firm dummies, and country dummies)]

\begin{tabular}{|c|c|c|c|c|}
\hline & predict $=2$ & predict $=1$ & predict $=0$ & total \\
\hline observe $=2$ & $\frac{88}{(.59)}$ & 45 & 16 & 149 \\
\hline observe $=1$ & 34 & $\frac{108}{(.50)}$ & 72 & 214 \\
\hline observe $=0$ & 4 & 39 & $\frac{591}{(.93)}$ & 634 \\
\hline total & 126 & 192 & 679 & $\frac{997}{(.79)}$ \\
\hline
\end{tabular}

Note:

In parentheses are the percentage of observations that are correctly predicted. For example in the first panel for predict $=2,80$ out $149(53 \%)$ of the observations are predicted correctly. For the model with only firm dummies $(80+83+588)$ out of 997 or $75 \%$ are correctly predicted. 
Table 4: Do firm attributes correlate with private information?

Dependent variable=LFDI(likelihood of FDD

[1]

[2]

$\begin{array}{lcc}\text { intercept } & -2.59 * * & -2.65^{* *} \\ & (0.13) & (0.27) \\ \text { past } & 2.23^{* *} & 2.04 * * \\ & (0.31) & (0.32) \\ \text { rival } & 1.49^{* *} & 1.49 * * \\ & (0.20) & (0.20) \\ \text { past*rival } & -0.90^{*} & -0.80^{*} \\ & (0.42) & (0.43) \\ \text { size } & & 0.00001^{*} \\ & & (8.753 \mathrm{E}-6) \\ \text { R\&D } & & 0.04 \\ & & (0.07) \\ \text { export propensity } & & -1.10^{*} \\ & & (0.56) \\ \mu & & 1.56 \\ \text { n } & & 840 \\ \text { logliklihood } & & -676.11 \\ & & \end{array}$

Note:

(1) Parentheses are standard errors. ** and * indicate $1 \%$ and $5 \%$ significance level, respectively.

(2) $\mu$ is the second intercept defining the threshold for the transition from LFDI equal to 1 to 2 . 
Table 5. Private information and firm size

\begin{tabular}{|c|c|c|c|}
\hline & [1] & [2] & [3] \\
\hline intercept & $\begin{array}{c}-2.23^{* *} \\
(0.14)\end{array}$ & $\begin{array}{c}-2.21 * * \\
(0.15)\end{array}$ & $\begin{array}{c}-2.18^{* *} \\
(0.15)\end{array}$ \\
\hline past & $\begin{array}{l}1.66^{* *} \\
(0.36)\end{array}$ & $\begin{array}{c}2.29 * * \\
(0.29)\end{array}$ & $\begin{array}{l}1.75^{* *} \\
(0.36)\end{array}$ \\
\hline rival & $\begin{array}{l}1.54^{* *} \\
(0.19)\end{array}$ & $\begin{array}{c}1.28^{* *} \\
(0.24)\end{array}$ & $\begin{array}{l}1.33^{* *} \\
(0.25)\end{array}$ \\
\hline past*rival & $\begin{array}{c}-0.68^{*} \\
(0.41)\end{array}$ & $\begin{array}{c}-1.00^{*} \\
(0.39)\end{array}$ & $\begin{array}{l}-0.65 \\
(0.41)\end{array}$ \\
\hline stratal & $\begin{array}{c}-1.25^{* *} \\
(0.24)\end{array}$ & $\begin{array}{c}-0.93 * * \\
(0.23)\end{array}$ & $\begin{array}{c}-1.22^{* *} \\
(0.25)\end{array}$ \\
\hline strata2 & $\begin{array}{c}-0.63^{* *} \\
(0.16)\end{array}$ & $\begin{array}{c}-0.76^{* *} \\
(0.18)\end{array}$ & $\begin{array}{c}-0.77^{* *} \\
(0.18)\end{array}$ \\
\hline past*stratal & $\begin{array}{l}2.68^{* *} \\
(0.68)\end{array}$ & & $\begin{array}{l}2.62^{* *} \\
(0.68)\end{array}$ \\
\hline past*strata2 & $\begin{array}{c}0.33 \\
(0.42)\end{array}$ & & $\begin{array}{c}0.11 \\
(0.44)\end{array}$ \\
\hline rival*stratal & & $\begin{array}{c}0.17 \\
(0.51)\end{array}$ & $\begin{array}{c}-0.21 \\
(0.57)\end{array}$ \\
\hline rival*strata2 & & $\begin{array}{l}0.68 * \\
(0.34)\end{array}$ & $\begin{array}{l}0.62^{*} \\
(0.36)\end{array}$ \\
\hline$\mu$ & 1.55 & 1.53 & 1.56 \\
\hline $\mathbf{n}$ & 997 & '997 & 997 \\
\hline logliklihood & -756.69 & -763.86 & -754.83 \\
\hline
\end{tabular}

Note:

(1) Parentheses are standard errors. ** and * indicate 1\% and 5\% significance level, respectively.

(2) $\mu$ is the second intercept defining the threshold for the transition from LFDI equal to 1 to 2 .

(3) Strata1=small firms, strata2=medium-sized firms, strata3=large firms: strata3 was used as the base. 
Table 6. Public information is complementary to private information

\begin{tabular}{|c|c|c|c|c|c|}
\hline & [1] & & [2] & & [3] \\
\hline \multirow[t]{2}{*}{ intercept } & $-2.47 * *$ & intercept & $-6.07 * *$ & intercept & $-2.43^{* *}$ \\
\hline & $(0.20)$ & & $(0.42)$ & & $(0.32)$ \\
\hline \multirow[t]{2}{*}{ past } & $2.27^{* *}$ & past & $2.87^{* *}$ & past & $2.02 * *$ \\
\hline & $(0.29)$ & & $(0.41)$ & & $(0.33)$ \\
\hline \multirow[t]{2}{*}{ rival } & $1.59 * *$ & rival & $1.84^{* *}$ & rival & $1.46 * *$ \\
\hline & $(0.19)$ & & $(0.29)$ & & $(0.21)$ \\
\hline \multirow{2}{*}{ past * rival } & $-0.93 *$ & past"rival & $-1.45^{* *}$ & past*rival & $-0.84 * *$ \\
\hline & $(0.40)$ & & $(0.53)$ & & $(0.43)$ \\
\hline \multirow[t]{2}{*}{ China } & $0.94 * *$ & China & $1.85^{* *}$ & China & $0.88 * *$ \\
\hline & $(0.24)$ & & $(0.31)$ & & $(0.26)$ \\
\hline \multirow[t]{2}{*}{ India } & $-1.17 * *$ & India & $-1.89 * *$ & India & $-1.28 * *$ \\
\hline & $(0.29)$ & & $(0.37)$ & & $(0.31)$ \\
\hline \multirow[t]{2}{*}{ Indonesia } & -0.17 & Indonesia & 0.02 & Indonesia & -0.24 \\
\hline & $(0.25)$ & & $(0.31)$ & & $(0.27)$ \\
\hline \multirow[t]{2}{*}{ Malaysia } & $-0.47 *$ & Malaysia & -0.55 & Malaysia & -0.41 \\
\hline & $(0.26)$ & & $(0.34)$ & & $(0.27)$ \\
\hline \multirow[t]{2}{*}{ Philippines } & $-0.94 * *$ & Philippines & $-1.24^{* *}$ & Philippines & $-1.04 * *$ \\
\hline & $(0.28)$ & & $(0.34)$ & & $(0.29)$ \\
\hline \multirow[t]{8}{*}{ Thailand } & -0.42 & Thailand & -0.20 & Thailand & -0.40 \\
\hline & $(0.26)$ & & $(0.33)$ & & $(0.28)$ \\
\hline & & & & size & $0.00002 *$ \\
\hline & & & & & (9.10E-6) \\
\hline & & & & export propensity & -1.13 \\
\hline & & & & & $(0.58)$ \\
\hline & & & & $\mathrm{R} \& \mathrm{D}$ & 0.04 \\
\hline & & & & & $(0.08)$ \\
\hline Firm dummies & No & & Yes & & No \\
\hline Country dummies & Yes & & Yes & & Yes \\
\hline$\mu$ & 1.61 & $\mu$ & 2.46 & $\mu$ & 1.67 \\
\hline $\mathbf{n}$ & 997 & $\mathbf{n}$ & 997 & $\mathbf{n}$ & 840 \\
\hline logliklihood & -736.78 & loglikelihood & -515.29 & loglikelihood & -637.98 \\
\hline
\end{tabular}

Note:

(1) Parentheses are standard errors. ** and * indicate $1 \%$ and $5 \%$ significance Ievel, respectively.

(2) $\mu$ is the second intercept defining the threshold for the transition from LFDI equal to 1 to 2.

(3) Vietnam was used as a base. 
Table 7: Country-specific value of private information

Dependent variable $=$ LFDI(likelihood of FDI)

\begin{tabular}{|c|c|c|c|c|c|c|c|}
\hline & China & India & Indo & Mal & Phil & Thai & Viet \\
\hline intercept & $\begin{array}{c}-1.25^{* *} \\
(0.24)\end{array}$ & $\begin{array}{c}-4.37 * * \\
(0.63)\end{array}$ & $\begin{array}{c}-2.73 * * \\
(0.33)\end{array}$ & $\begin{array}{c}-3.24 * * \\
(0.38)\end{array}$ & $\begin{array}{c}-3.64 * * \\
(0.49)\end{array}$ & $\begin{array}{c}-2.45^{* *} \\
(0.33)\end{array}$ & $\begin{array}{c}-2.89 * * \\
(0.37)\end{array}$ \\
\hline past & $\begin{array}{c}2.60 * * \\
(0.82)\end{array}$ & $\begin{array}{c}2.01 \\
(1.35)\end{array}$ & $\begin{array}{c}2.13^{* *} \\
(0.66)\end{array}$ & $\begin{array}{l}3.00^{* * *} \\
(0.66)\end{array}$ & $\begin{array}{l}2.66^{*} \\
(1.16)\end{array}$ & $\begin{array}{l}1.37 * \\
(0.57)\end{array}$ & $\begin{array}{c}-2.7 \mathrm{E}-16 \\
(1.45)\end{array}$ \\
\hline rival & $\begin{array}{l}1.24^{* *} \\
(0.42)\end{array}$ & $\begin{array}{c}2.38 * * \\
(0.70)\end{array}$ & $\begin{array}{l}1.75^{* *} \\
(0.47)\end{array}$ & $\begin{array}{l}1.82^{* *} \\
(0.49)\end{array}$ & $\begin{array}{c}0.82 \\
(0.58)\end{array}$ & $\begin{array}{c}1.02^{*} \\
(0.46)\end{array}$ & $\begin{array}{l}3.10^{* *} \\
(0.73)\end{array}$ \\
\hline past*rival & $\begin{array}{l}-0.98 \\
(1.09)\end{array}$ & $\begin{array}{c}24.17 \\
(127372)\end{array}$ & $\begin{array}{l}-1.02 \\
(0.91)\end{array}$ & $\begin{array}{l}-1.95^{*} \\
(0.85)\end{array}$ & $\begin{array}{c}0.94 \\
(1.74)\end{array}$ & $\begin{array}{c}0.05 \\
(0.79)\end{array}$ & $\begin{array}{c}0 \\
(0)\end{array}$ \\
\hline$\mu$ & 1.22 & 2.19 & 1.71 & 1.89 & 1.95 & 1.45 & 1.96 \\
\hline $\mathbf{n}$ & 141 & 152 & 143 & 141 & 145 & 133 & 142 \\
\hline logliklihood & -133.32 & -61.46 & -117.83 & -108.80 & -79.37 & -116.69 & -106.01 \\
\hline
\end{tabular}

Note:

(1) Parentheses are standard errors. $* *$ and $*$ indicate $1 \%$ and $5 \%$ significance level, respectively.

(2) $\mu$ is the second intercept defining the threshold for the transition from LFDI equal to 1 to 2 . 
Table 8. The role of FDI policy and labor costs

Dependent variable=LFDI (likelihood of FDI)

\begin{tabular}{|c|c|c|c|c|c|c|c|c|c|}
\hline & [1] & [2] & [3] & [4] & & [5] & [6] & [7] & [8] \\
\hline intercept & $\begin{array}{c}-2.82 * * \\
(0.33)\end{array}$ & $\begin{array}{c}-3.58^{* *} \\
(0.52)\end{array}$ & $\begin{array}{c}-4.05^{* *} \\
(0.56)\end{array}$ & $\begin{array}{c}-4.16^{* *} \\
(0.58)\end{array}$ & intercept & $\begin{array}{c}-2.75^{* *} \\
(0.26)\end{array}$ & $\begin{array}{c}-5.81^{* *} \\
(0.67)\end{array}$ & $\begin{array}{c}-5.60 * * \\
(0.72)\end{array}$ & $\begin{array}{c}-4.77^{* *} \\
(0.71)\end{array}$ \\
\hline past & $\begin{array}{c}2.31^{* *} \\
(0.41)\end{array}$ & $\begin{array}{l}2.01 * * \\
(0.44)\end{array}$ & $\begin{array}{l}4.11^{* *} \\
(1.00)\end{array}$ & $\begin{array}{l}1.85^{* *} \\
(0.45)\end{array}$ & past & $\begin{array}{l}2.14^{* *} \\
(0.38)\end{array}$ & $\begin{array}{l}2.51^{* *} \\
(0.40)\end{array}$ & $\begin{array}{c}1.71 \\
(1.16)\end{array}$ & $\begin{array}{l}2.41^{* *} \\
(0.40)\end{array}$ \\
\hline rival & $\begin{array}{l}1.87 * * \\
(0.34)\end{array}$ & $\begin{array}{l}1.69 * * \\
(0.35)\end{array}$ & $\begin{array}{l}1.60^{* *} \\
(0.35)\end{array}$ & $\begin{array}{c}3.99 * * \\
(0.98)\end{array}$ & rival & $\begin{array}{l}1.73^{* *} \\
(0.32)\end{array}$ & $\begin{array}{l}1.98 * * \\
(0.33)\end{array}$ & $\begin{array}{l}1.96 * * \\
(0.33)\end{array}$ & $\begin{array}{l}-1.55 \\
(1.13)\end{array}$ \\
\hline pa_ri & $\begin{array}{l}-0.99 * \\
(0.57)\end{array}$ & $\begin{array}{l}-0.86 \\
(0.58)\end{array}$ & $\begin{array}{l}-0.49 \\
(0.59)\end{array}$ & $\begin{array}{l}-0.35 \\
(0.61)\end{array}$ & pa_ri & $\begin{array}{l}-0.88^{*} \\
(0.53)\end{array}$ & $\begin{array}{l}-1.34^{*} \\
(0.55)\end{array}$ & $\begin{array}{l}-1.37 * \\
(0.55)\end{array}$ & $\begin{array}{l}-1.32 * \\
(0.55)\end{array}$ \\
\hline FDIplcy & & $\begin{array}{l}0.17^{*} \\
(0.08)\end{array}$ & $\begin{array}{c}0.27^{* *} \\
(0.09)\end{array}$ & $\begin{array}{c}0.31 * * \\
(0.10)\end{array}$ & labor cost & & $\begin{array}{c}0.39 * * \\
(0.07)\end{array}$ & $\begin{array}{c}0.37 * * \\
(0.08)\end{array}$ & $\begin{array}{c}0.25^{* *} \\
(0.08)\end{array}$ \\
\hline FDlplcy*past & & & $\begin{array}{l}-0.38^{*} \\
(0.16)\end{array}$ & & Icost ${ }^{*}$ past & & & $\begin{array}{c}0.11 \\
(0.15)\end{array}$ & \\
\hline FDIplcy*rival & & & & $\begin{array}{l}-0.44^{*} \\
(0.17)\end{array}$ & lcost ${ }^{*}$ rival & & & & $\begin{array}{c}0.50^{*} \\
(0.15)\end{array}$ \\
\hline$\mu$ & 2.03 & 2.05 & 2.07 & 2.06 & $\mu$ & 1.88 & 1.96 & 1.97 & 2.01 \\
\hline firm dummies & yes & yes & yes & yes & firm dummies & yes & yes & yes & yes \\
\hline $\mathbf{n}$ & 427 & 427 & 427 & 427 & $\mathbf{n}$ & 480 & 480 & 480 & 480 \\
\hline logliklihood & -336.02 & -334.12 & -331.36 & -330.88 & logliklihood & -385.28 & -370.71 & -370.44 & -365.17 \\
\hline
\end{tabular}

Note:

(1) Parentheses are standard errors. ${ }^{* *}$ and $*$ indicate $1 \%$ and $5 \%$ significance level respectively.

(2) $\mu$ is the second intercept defining the threshold for the transition from LFDI equal to 1 to 2 .

(3) 67 firm dummies were included in the regressions. 


Title

WPS1719 Shifting Responsibility for Social Services As Enterprises Privatize in Belarus

WPS1720 The Distribution of Foreign Direct Investment in China

WPS1721 EU Accession of Central and Eastern Europe. Bridging the Income Gap

WPS1722 Uncertainty, Instability, and Ireversible investment. Theory, Evicence, and Lessons for Africa

WPS1723 The Productivity Effects of of Decentralized Reforms: An Analysis of the Chinese industrial Reforms

WPS1724 Debt Maturity and Firm Performance A Panel Study of Indian Companies

WPS1725 Access to Long-Term Debt and Effects on Firms' Performance: Lessons form Ecuador

WPS1726 Roads, Population Pressures, and Deforestation in Thailand, 1976-89

WPS1727 The Economics of the Informal Sector: A Simple Model and Some Empirical Evidence from Latin America

WPS1728 Regional Labor Markets during Deregulation in indonesia: Have the Outer Islands Been Left Behind?

WPS1729 Does Mercosur's Trade Performance Raise Concerns about the Effects of Regional Trade Arrangements?

WPS1730 Have Trade Policy Reforms Led to Greater Openness in Developing countries?

WPS1731 Pension Reform, Growth, and the Labor Market in Ukraine

\section{Author}

David Sewell

Harry G. Broadman

Xiaolun Sun

Luca Barbone

Juan Zalduendo

Luis Servén

Lixin Colin $X u$

Fabic Schiantarelli

Vivek Srivastava

Fidel Jaramilio

Fabio Schiantarelli

Maureen Cropper

Charles Griffiths

Muthukumara Mani

Norman A. Loayza

Chris Manning

Alexander Yeats

Shuby Andriamananjara

John Nash

Michelle Riboud

Hoaquan Chu
February 1997

February 1997

February 1997

February 1997

A. Maranon 39074

Contact

C. Lawrence 32216

J. Grigsby

82423

L. Barbone 32556

E. Khine 37471

P. Sintim-Aboagye 38526

B. Moore 38526

B. Moore 38526

R. Martin 39026

February 1997

J. Israel 85117

February 1997 J. Ngaine 37947

February 1997

J. Ngaine 37959

February 1997

R. Hablero 33971 for paper 


\section{Policy Research Working Paper Series}

\begin{tabular}{|c|c|c|c|c|}
\hline & Title & Author & Date & $\begin{array}{l}\text { Contact } \\
\text { for paper }\end{array}$ \\
\hline WPS1732 & $\begin{array}{l}\text { Agricultural Trade and Rural } \\
\text { Development in the Middle East } \\
\text { and North Africa: Recent Development } \\
\text { and Prospects }\end{array}$ & $\begin{array}{l}\text { Dean A. DeRosa } \\
\text { ts }\end{array}$ & February 1997 & $\begin{array}{l}\text { J. Ngaine } \\
37959\end{array}$ \\
\hline WPS1733 & $\begin{array}{l}\text { The Usefulness of Private and Public } \\
\text { Information for Foreign Investment } \\
\text { Decisions }\end{array}$ & $\begin{array}{l}\text { Yuko Konoshita } \\
\text { Ashoka Mody }\end{array}$ & February 1997 & $\begin{array}{l}\text { R. Reff } \\
34815\end{array}$ \\
\hline
\end{tabular}

